\title{
Application Strategies of Cloud Computing Intelligent Optimization Algorithms in English Translation Major Teaching
}

\author{
Wanfang Zhang ${ }^{1}$ and Hexiao Yin $\mathbb{D}^{2}$ \\ ${ }^{1}$ School of Foreign Languages, Wuhan Polytechnic University, Wuhan 430023, Hubei, China \\ ${ }^{2}$ School of Criminal Law, East China University of Political Science and Law, Shanghai 201620, China \\ Correspondence should be addressed to Hexiao Yin; 2945@ecupl.edu.cn
}

Received 23 August 2021; Revised 30 September 2021; Accepted 15 October 2021; Published 26 October 2021

Academic Editor: Sang-Bing Tsai

Copyright (c) 2021 Wanfang Zhang and Hexiao Yin. This is an open access article distributed under the Creative Commons Attribution License, which permits unrestricted use, distribution, and reproduction in any medium, provided the original work is properly cited.

With the development of social economy, English is still the main language of global communication, and China's demand for
English translators is also higher and higher. In college education, English translation is a very popular and important subject.
Although the teaching mode is constantly changing, it still lags behind the speed of social and economic development. Traditional
English translation teaching has many disadvantages in teaching theory and methods. This paper discusses the problems existing
in translation teaching for English majors and then puts forward a new teaching mode of educational multiattitude resources, to
really improve the quality of translation teaching for English majors. The resource pool of cloud computing is composed of a large
number of resource nodes with different performances, but as the number of users gradually grows, the demand also increases.
How to efficiently allocate large-scale cloud tasks to limited resource nodes and to achieve load balancing is an important issue that
needs to be studied in cloud computing. This paper first uses the literature method, in-depth study of the theoretical development,
and application bottleneck of education multiposture teaching mode at the same time to understand the problems existing in the
current English translation teaching and design a new teaching mode for experimental application research and finally analyzes
the comparison of the English translation ability of the control group and the experimental group without teaching method. After
a period of experiment, the average score of the control group is 70.53 , and the average score of the experimental group is 75.89 . It
can be seen that the average score of the experimental group is about 5 points higher than that of the control group; this shows that
the intelligent optimization algorithm of cloud computing is combined with translation teaching that can improve the students'
overall English translation level to a certain extent and is more conducive to the students' comprehensive mastery of knowledge.

\section{Introduction}

With the advent of the information age, the rapid development of information technology represented by computers, networks, and information equipment has greatly changed people's work, English translation studies, and lifestyles. The application of information technology in the field of education and the deep integration of English teaching has promoted the development of education informatization. The level of informatization of education indicates the degree of informatization of the country, and the key to the informatization of education is to have a group of high-quality teachers. For this reason, the country attaches great importance to the cultivation of teacher informatization and teaching ability. The emergence of cloud computing has greatly promoted the development of mobile learning. Infrastructure as a service (IaaS) greatly reduces the hardware requirements of mobile learning; software as a service (SaaS) solves the problem of crossplatform compatibility of learning systems; platform as a service (PaaS) is a service form of mobile learning system development, and shared utilization has created favorable conditions. Mobile learning has been considered a learning model with great development potential from the day it came into being. With the powerful power of cloud computing, it can be said that mobile learning based on cloud computing will definitely become an indispensable learning model for future learning. The application of cloud 
computing technology in the field of teaching has played an important role in promoting the development of education, informatization, and modernization. Cloud computing technology can improve teaching quality and realize the sharing of teaching resources, which is of great significance to promoting teaching. The application of cloud computing technology in the field of education has changed the traditional learning methods of learners and provided learners with a collaborative development platform. Teachers can design courses according to the characteristics of their respective subjects, integrate teaching resources, and improve teaching and learning methods. The application of cloud computing technology to foreign language teaching will promote the new development of foreign language teaching concepts, models, content, and teaching effects so that the level of foreign language teaching informatization will reach a new height.

Teachers must have high information literacy. To understand and master the basic concepts of educational technology and cloud computing teaching concepts, teachers can only carry out information technology and curriculum integration scientifically and effectively if they have good information literacy; second, teachers must have information technology knowledge and skills. Teachers should keep up with the pace of the times, update information technology knowledge in a timely manner, and be proficient in information technology tools. The application significance of cloud computing in college English teaching is reflected in these four aspects: to stimulate students' awareness of active participation, break the time and space limitations of English teaching, provide massive education and teaching resources, and promote multiple interactions in English learning. The main reason is that the application of cloud computing in college English teaching is changing students' cognitive styles. Students change from passively accepting knowledge to actively constructing knowledge; breaking the monopoly of educational resources and providing massive educational and teaching resources through "Cloud services" will realize effective resource sharing. In this regard, teachers can explore the potential of students' self-learning through the study of English translation teaching and develop the habit of students using translation skills reasonably. The application of the cloud computing intelligent optimization algorithm in the teaching of English translation major will achieve better teaching results. The integration of intelligent algorithms and courses is an important part of our country's basic education reform. The integration of intelligent algorithms and courses is not simply the use of intelligent algorithms in teaching but the active integration of subjects and courses in a deep level. The integration of intelligent algorithms and courses emphasizes that teachers use intelligent algorithms to create a contextual learning environment related to the teaching content and fully mobilize and maintain students' learning motivation.

With the development of education informatization, China has invested a lot of manpower and material resources in the construction, sharing, and management of software and hardware of teaching resources, and China's teaching resources have shown a geometric growth. However, due to the differences in regional economic development, there are still some problems in the construction and sharing of teaching resource platforms in China, such as unbalanced regional development, uneven distribution, low originality, slow updating speed, high updating cost, imbalanced team building, and low user satisfaction. Bahri believed that the use of mobile devices in English translation teaching can achieve good teaching effect and promote the development of translation education [1]. Kim pointed out that the translation errors of long sentences and complex sentences are the most in English translation, and it can promote their reading comprehension ability and background culture ability [2]. Yi proposed to bring the multimode approach into teacher education, but it did not specifically talk about how to carry out the educational behavior and action of the mode [3]. In the current situation of teaching resources informatization, there are problems such as uneven distribution of teaching resources, outdated resources, little original data, low user satisfaction, slow update speed, high update cost, low sharing level, and imbalanced teacher team construction. We must look for problems solved by new technical means.

The innovation of this paper lies in (1) the combination of qualitative analysis and quantitative analysis which is based on the analysis of big data and (2) combining theoretical research with empirical research, emphasizing the theoretical results of cloud computing intelligent optimization algorithms, and conducting empirical analysis based on specific conditions in the application of actual English translation teaching [4]. By analyzing the characteristics of cloud computing and the status quo of the informatization of teaching resources, it is found that the sharing of teaching resources based on cloud computing has the advantages of safer data, more convenient access, more cost-saving, richer applications, and unlimited storage space [5]. It is aimed at current teaching. The problems of resource informatization make it possible to realize resource sharing and education equity.

\section{Applied Strategies of Cloud Computing Intelligent Optimization Algorithms in the Teaching of English Translation Majors}

2.1. Current Situation of Traditional English Translation Teaching. With the continuous improvement of college English translation students' English level, the education department has carried out the reform of college English translation teaching and made corresponding adjustments to the English translation curriculum. The translation textbooks for English majors are constantly updated, including translation exercises, English translation, English practice, and so on [6]. Moreover, the education is strengthened to better assist professional translation teaching. In the teaching of college English majors, the translation classroom teaching is teacher centered, which cannot let students learn independently in the classroom. Most students' English translation learning depends on the help of teachers and cannot understand and think 
independently, so it is necessary to reform the translation of English majors [7, 8]. In the traditional translation teaching for English majors, there are many translation exercises related to translation tasks and textbook knowledge, which cannot arouse students' interest. When teachers teach, they usually focus on the content of teaching materials, which are designed and arranged by teachers according to the teaching materials, so it is difficult to innovate in teaching [9]. The purpose of teaching is more for examination than application. Even if the students pass the grade examination, English translation ability is still limited to exam oriented, and they cannot translate correctly [10].

In the process of classroom teaching, there are often some students with weak English foundation who are resistant to English expression, and they cannot complete the classroom teaching task well [11]. English translation is usually full of grammatical mistakes and tongue twisters. These English translations are not up to the standard, and the meaning is relatively vague [12]. After the students translate the exercises, the translation often deviates from the original meaning [13]. Students know how to translate, but they cannot express their inner thoughts correctly. If you cannot understand it correctly, you should follow your own way of thinking and roughly copy it mechanically according to the meaning of the words you have mastered. As a result, the grammatical structure of English translation is confused; the logic is not clear, and at the same time, there will be omissions, word filling, and grammatical errors [14]. Therefore, based on the above situation, to achieve the purpose of teaching is a very difficult thing [15]. Especially those students with poor English foundation, it is difficult for them to understand the teaching content like those with strong English translation ability. We also found that increasingly students think that the college English course is just a simple repetition of what they have learned so that increasingly students are not interested in the course frequently $[16,17]$. Furthermore, it is gradually missing. There are increasingly English translation questions in the $\mathrm{Na}$ tional English proficiency test, but there are still only a few simple translation sentences, and the score of English translation questions is relatively low, so the proportion of English translation questions in the whole exam is relatively low, which has objectively caused a lot of negative effects on college English translation teaching [18].

\subsection{Application of Cloud Computing in Education and} Teaching. In a sense, the education system is a complex information system including people [19]. The introduction of information input methods should provide effective methods for educational researchers to analyze the educational information processing systems.

It was physicist R. Clausius first proposed the term entropy. The entropy he proposed is now called thermal entropy. This is the operating state of the thermodynamic system.

$$
S=\int \frac{\mathrm{d} Q}{T} .
$$

However, Boltzmann studied the relationship between $\mathrm{S}$ and thermodynamic $\Omega$ as follows:

$$
S \propto \ln \Omega,
$$

where $\Omega$ is the number of microstates corresponding to the macrostate of the corresponding system. In 1900, after Planck proposed Boltzmann's constant $K$, he obtained the Boltzmann relation:

$$
S=k \ln \Omega .
$$

Thermal entropy is the scale of disturbance in a natural systems. The larger the $\Omega$, the more likely there will be in the physical system. From the micropoint of view, the system is more diverse and has no rules to follow.

The value of the random variable is uncertain. Before the random experiment, only the probability distribution of each value was known. Through random experiments, the accurate price is obtained, and the uncertainty is completely eliminated.

When Shannon studied the uncertainty measurement of random variables, the formula obtained was the same as the thermal entropy at the mathematical model level [20]. Therefore, the measurement of random uncertain variables is also called entropy, which is now generally called information entropy or Shannon entropy. In this way, information is obtained through random experiments. The amount of information is the entropy of the random variable. In this sense, entropy can be used as a measure of information.

The information entropy function is as follows:

$$
H\left(p_{1}, p_{2}, \ldots, p_{n}\right)=-\sum_{n=1}^{1} p_{n} \log p_{n} .
$$

When there are multiple random variables, to distinguish the entropy of different random variables, the entropy can be written as $H(x)$ and $H(y)$ to represent the entropy of $X$ or $Y$, respectively.

Entropy has a series of useful properties:

$$
H\left(p_{1}, p_{2}, \ldots, p_{n}\right) \leq \log n,
$$

where the equal sign holds if and only if $a=\log (I=1,2, \ldots, n)$, which indicates that the entropy of the equal probability field is the largest when the number of basic events (States) is the same.

$$
H\left(p_{1}, p_{2}, \ldots, p_{n}\right) \geq 0
$$

The equal sign holds if and only if $x$ is a degenerate distribution, which indicates that the entropy of the deterministic field (nonrandom field) is minimum. 
Let $y$ be another discrete random variable, $H(x, y)$ be the joint entropy of $X$ and $y$, and $H(x \mid y)$ be the conditional entropy of $X$ when $y$ is known:

$$
\begin{aligned}
& H(X, Y)=H(X)+H(Y), \\
& H(X \mid Y) \leq H(X), \\
& H(X \mid Y) \leq H(Y) .
\end{aligned}
$$

\section{Experiments on the Application Strategy of Cloud Computing Intelligent Optimization Algorithm in the Teaching of English Translation Major}

The current situation of teaching research on educational multiposture resources is mainly based on theoretical research, on practice, and the selected research elements are not comprehensive enough. Therefore, this paper chooses a college English translation education for teaching research experiment; the purpose is to compare the traditional English translation education to highlight the teaching achievements of multiattitude education resources in English translation teaching.

In this paper, the students of English translation major are divided into the control group and the experimental group. The control group follows the traditional teaching mode, mainly in the form of theoretical explanation. In addition to explaining the basic knowledge of textbooks, it also teaches translation skills. The experimental group uses the cloud computing intelligent optimization algorithm to assist English translation teaching mode to teach; on the one hand, it adopts a variety of teaching methods; on the other hand, different contexts and situations are set in each course so that students can learn practical translation contexts and skills for more colorful teaching, grasp the key points of translation in different occasions, and easily master keyword translation, to improve students' professional translation ability and realize good communication ability.

This experiment is divided into two stages, namely, before and after the experiment, and the two stages are tested to compare the teaching effect in the most direct form of performance. The English translation teaching experiment constructed in this paper mainly focuses on students' English level, situation recognition ability, and language expression ability. It is hoped that the teaching mode proposed in this paper can be of great help to both students and teachers.

\section{Application Strategies of Cloud Computing Intelligent Optimization Algorithms in English Translation Major Teaching}

It can be seen from Table 1 and Figure 1 that the scores of the experimental group and the control group are almost the same, but the overall level is low. After a period of experiment, the average score of the control group is 70.53 points, and the average score of the experimental group is 75.89 points. It can be seen that the average score of the experimental group is about 5 points higher than that of the control group; this well reflects that the application of cloud computing intelligent optimization algorithms to translation teaching can improve students' overall English proficiency to a certain extent, and it is also more conducive to students' mastery of knowledge. The pace of education informatization in China is in full swing. Internet technology is developing rapidly in the direction of broadband and multimedia, and the integration of education, informatization, and teaching resources is also advancing rapidly. China currently focuses on the construction of teaching resources and has invested heavily in the construction, sharing, and management of software and hardware resources, resulting in a geometric growth of teaching resources.

With the birth of the teaching resource library design based on the traditional network B/S structure, it has become a turning point in the research process of information technology integration teaching resources, which greatly improves the limitations of the traditional campus network teaching resource sharing. The $\mathrm{B} / \mathrm{S}$ structure of the teaching resource library realizes an open resource organization structure, and administrators and users collect the data that need to be included in the library; then, the server will be handed over to the server to implement a unified management of data resources, to maximize the sharing of teaching resources; the general $\mathrm{B} / \mathrm{S}$ method provides openness and flexibility for the provision and acquisition of teaching resources, and the use method is general, and the platform can be expanded.

It can be seen from Table 2 and Figure 2 that the average score of the experimental group before the experiment is lower than that of the control group, but after the experiment of different teaching methods, the score of the experimental group is 78.59 points, while that of the control group is 71.33 points.

Integrating teaching resources will help to improve the enthusiasm of all teaching workers for the use of educational technology and the development of online courses, help strengthen the level of modern teaching technology, and be a powerful means to deepen the reform of education and teaching. In the requirements of curriculum reform, we have always supported the use of information technology to change the way students learn and provide a variety of rich learning resources and tools.

It can be seen from the sample test results that Table 3 and Figure 3 clearly highlight that the experimental group performs better than the control group, and the average score is higher than the control group; the standard deviation of the control group is 3.121, and the standard deviation of the experimental group is 1.803 ; the standard error of the control group is 0.6012 , and the standard error of the experimental group is 0.4653 ; the $T$ value of the control group is 9.985, and the $T$ value of the experimental group is 11.317 .

There are existing problems of uneven distribution of teaching resources, slow update speed, and low degree of sharing. At the same time, the current education informatization construction pays attention to hardware but ignores software applications, resulting in a waste of resources and a low utilization rate. In addition, the teaching resource library based on the B/S structure provides less teaching software. 
Table 1: Sample statistics of the English proficiency test.

\begin{tabular}{|c|c|c|c|c|c|}
\hline Group & Experimental stage & Mean value & $N$ & Standard deviation & Standard error of mean \\
\hline Control group & $\begin{array}{l}\text { Before the experiment } \\
\text { After the experiment }\end{array}$ & $\begin{array}{l}66.58 \\
70.53\end{array}$ & $\begin{array}{l}45 \\
45\end{array}$ & 10.793 & 1.609 \\
\hline Experiment group & $\begin{array}{l}\text { Before the experiment } \\
\text { After the experiment }\end{array}$ & $\begin{array}{l}67.71 \\
75.89\end{array}$ & $\begin{array}{l}45 \\
45\end{array}$ & 8.947 & 1.334 \\
\hline
\end{tabular}

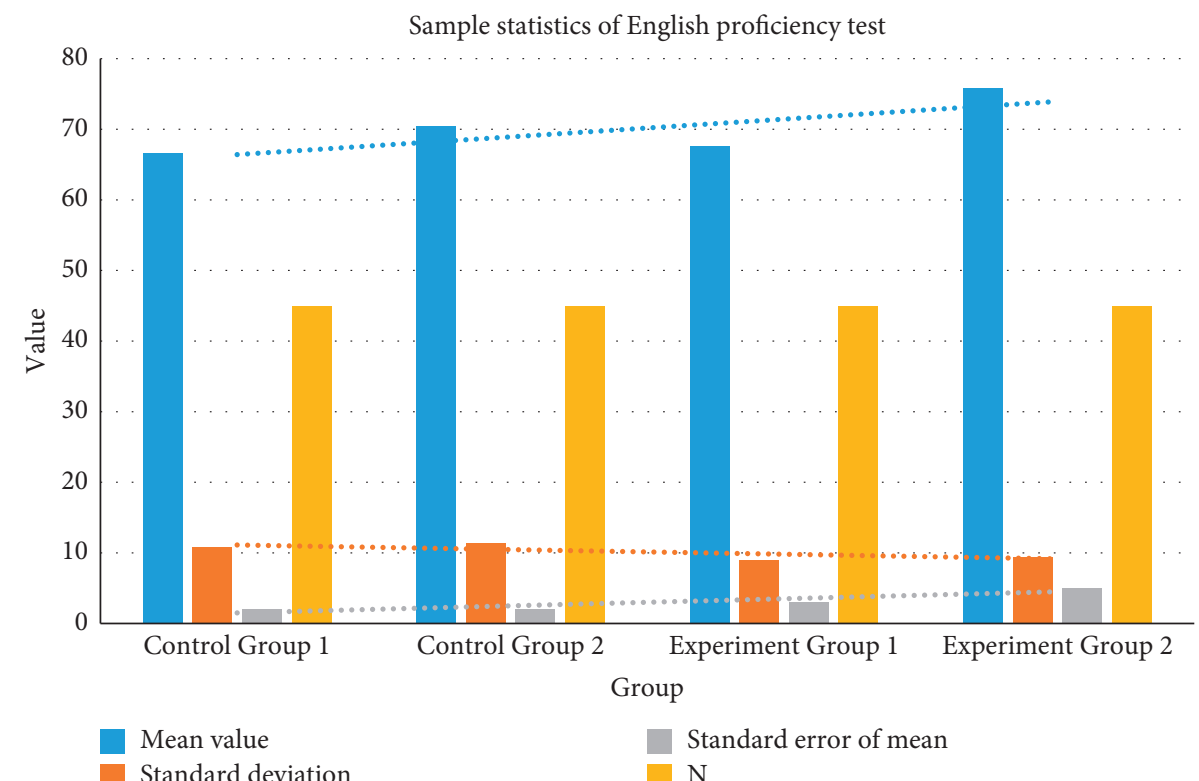

Standard deviation

$\mathrm{N}$

FIGURE 1: Sample statistics of the English proficiency test.

TABLE 2: Sample statistics of the English translation proficiency test.

\begin{tabular}{lccccc}
\hline Group & Experimental stage & Mean value & $N$ & Standard deviation & Standard error of mean \\
\hline \multirow{2}{*}{ Control group } & Before the experiment & 68.52 & 45 & \multirow{2}{*}{3.598} & \multirow{2}{*}{1.198} \\
& After the experiment & 71.33 & 45 & 45 & \multirow{2}{*}{1.383} \\
\multirow{2}{*}{ Experiment group } & Before the experiment & 67.69 & 458 & 45 \\
\hline
\end{tabular}

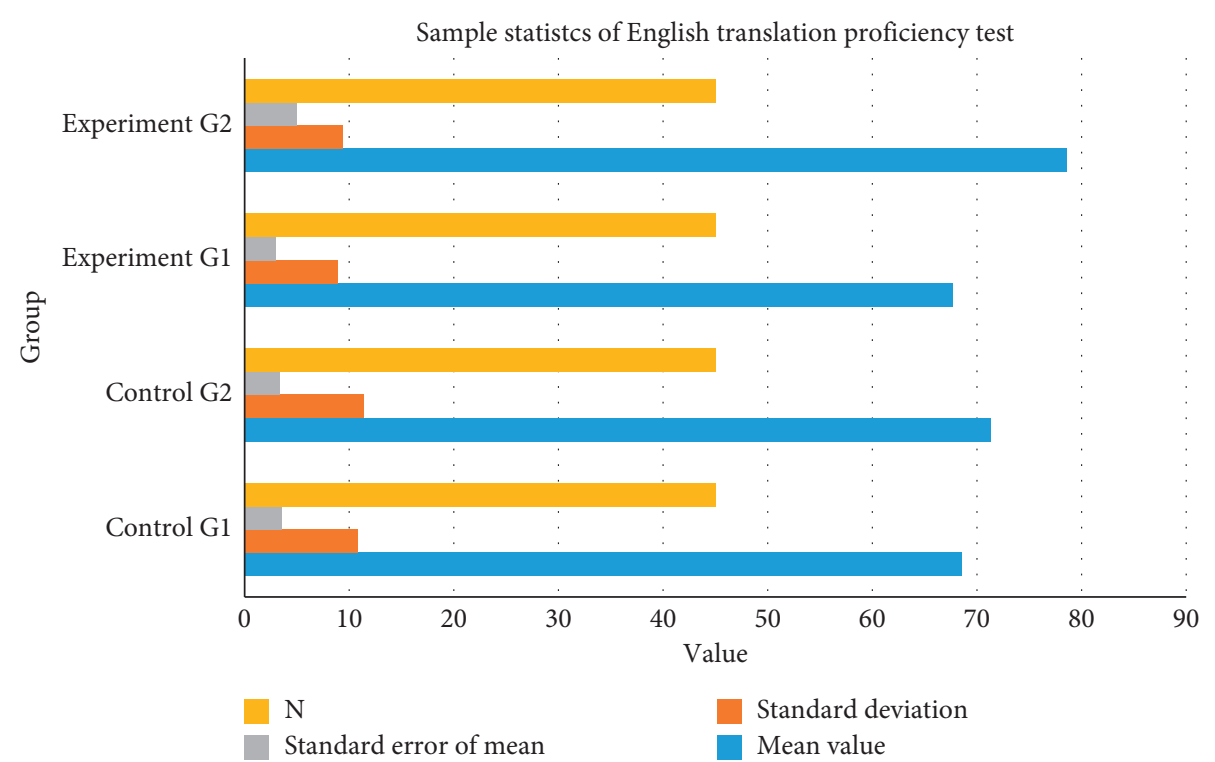

FIgURE 2: Sample statistics of the English translation proficiency test. 
TABle 3: Sample test.

\begin{tabular}{|c|c|c|c|c|c|c|c|c|}
\hline \multirow{3}{*}{ Grouping } & & & Pairwise difference & \multirow{2}{*}{\multicolumn{2}{|c|}{$\begin{array}{l}\text { 95\% confidence interval of } \\
\text { difference }\end{array}$}} & \multirow{3}{*}{$t$} & \multirow{3}{*}{ Df } & \multirow{3}{*}{ P (bilateral) } \\
\hline & \multirow[t]{2}{*}{ Mean value } & \multirow{2}{*}{ Standard deviation } & \multirow{2}{*}{ Standard error of mean } & & & & & \\
\hline & & & & Lower limit & Upper limit & & & \\
\hline Control group & 5.181 & 3.121 & 0.6012 & 4.614 & 7.386 & 9.98 & 8 & 0 \\
\hline Experience group & 6.123 & 1.803 & 0.4653 & 4.244 & 6.119 & 11.31 & 15 & 0 \\
\hline
\end{tabular}

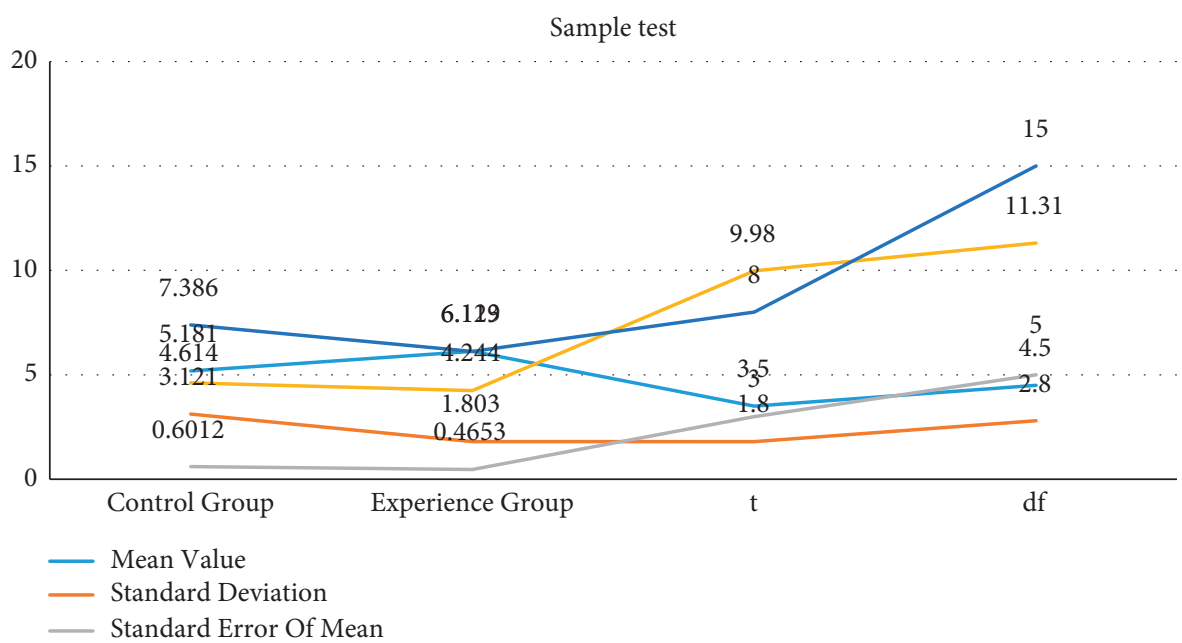

Figure 3: Sample test.

TABLE 4: The satisfaction evaluation of students and teachers with this mode of teaching.

\begin{tabular}{lcccccc}
\hline Type & Very satisfied & Satisfied & Commonly & Dissatisfied & Very dissatisfied & General evaluation \\
\hline Student & $46(50.32)$ & $15(22.79)$ & $8(18.76)$ & $16(23.58)$ & $5(12.54)$ & 87.56 \\
Teacher & $15(56.78)$ & $5(20.00)$ & $3(17.69)$ & $3(17.69)$ & $2(15.43)$ & 88.35 \\
\hline
\end{tabular}

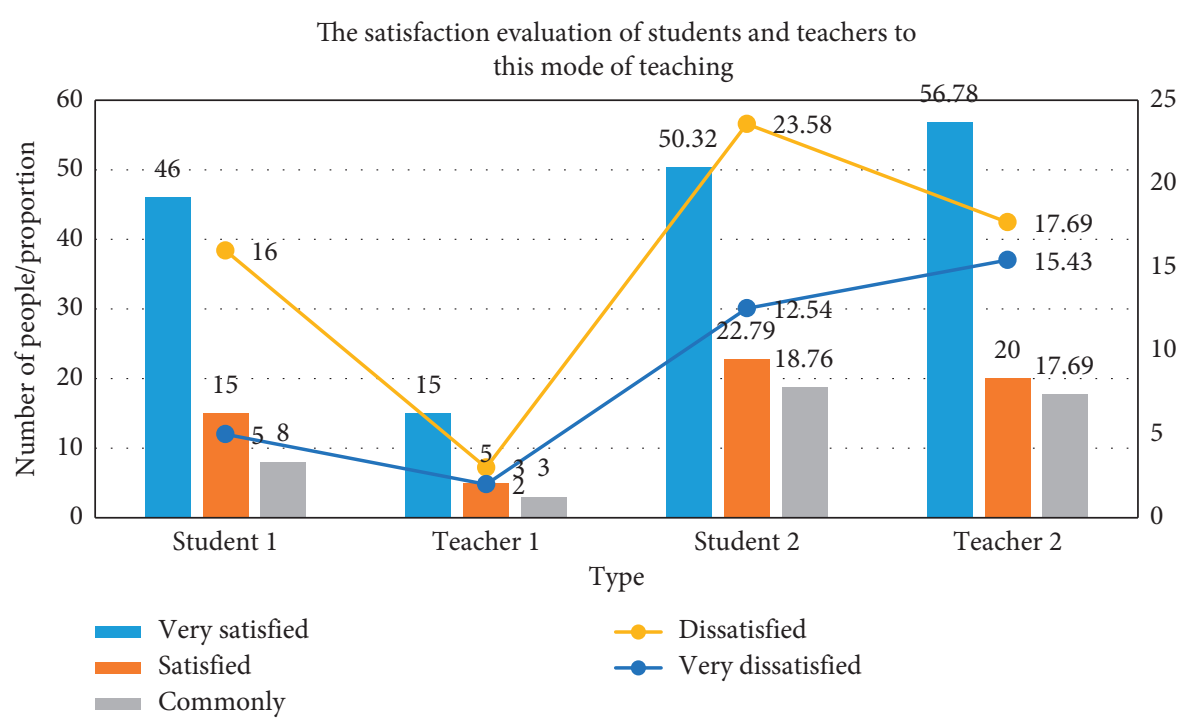

FIGURE 4: The satisfaction evaluation of students and teachers with this mode of teaching. 
How to effectively solve the problem of integrating teaching resources in the network is imminent. Researchers from various countries are turning their attention to cloud computing.

From Table 4 and Figure 4, we can see that there are 90 students in our two classes, of which 46 are very satisfied with the attitude; that is, more than half of the students are very satisfied with this kind of teaching method and think that this kind of teaching mode can better let them master the knowledge and make the classroom more lively and interesting. We interviewed 25 English teachers in our university, and 15 of them were satisfied with this teaching method, accounting for $56.78 \%$.

\section{Conclusion}

The educational reform that promotes the transformation of learning, teaching, and management methods, realizes educational fairness, and promotes educational balance is about to kick off. The promotion of policies has promoted all parties' capital to the field of education informatization. The development of cloud computing technology in the field of vocational education has initially reached a scale, and there have been many attempts in the field of basic education. Cloud technology has added impetus to the education platform. Every progress in science and technology is accompanied by a change in the field of education. Every change in the field of education must derive a new educational concept. The emergence of every educational theory will definitely change the face of teaching, and the improvement of teaching level will promote science. The technology advances again. From the early simple teaching aids to teaching machines and from the application of multimedia courseware to computer-assisted teaching, to the emergence of cloud computing, a new path has appeared in front of educators. I believe there will be a complete science education theory based on cloud computing, with the continuous development and improvement of cloud computing technology. The increasing demand of learners for information acquisition and services has prompted online learning websites to provide increasingly Internet services, and these Internet services need to process a large amount of data, which increases the load of the Internet system. How to not only meet the teaching requirements for massive data and services but also control the cost-effective investment and at the same time achieve an effective sharing mechanism will be the topic we need to study.

The innovation of this paper lies in the following: first, the combination of qualitative analysis and quantitative analysis, and second, the combination of theoretical research and empirical research, while emphasizing the theoretical results of cloud computing intelligent optimization algorithms, it also conducts empirical analysis based on the specific situations in the actual application of English translation teaching.

Cloud computing has the ability to provide new ideas and solutions for the education field. The low cost, highly interactive, and collaborative learning characteristics required in the education field can be realized by cloud computing, and it has the potential to obtain global resources. There are still some shortcomings in this paper, mainly based on the research status of multiattitude resource teaching mode. First of all, due to many reasons, it is difficult to determine the interaction value and limitations of various modes of the whole system. Therefore, influenced by many factors, subjective perception will produce different analysis results, and the translation will be very different. Second, regarding researchers and participants, the research and practical education of multilingual translation mainly focus on systemic functional linguistics and translation teachers and the interdisciplinary translation, because it is crossdisciplinary, other departments need to cooperate with professional teachers and students in research. Such translation can more fully reflect the need. Third, in terms of function, cloud computing intelligent optimization algorithm assisted teaching needs higher digital technical support in educational practice, which brings difficulties to the allocation of university software equipment in China. Educational informatization is gradually developing and progressing. The education system needs information technology that can provide users with super storage, computing capabilities, and online teaching software and other services, and new cloud computing technology can meet the above requirements. At the same time, the low cost of cloud computing has become an important reason for educational institutions to introduce cloud. Therefore, the introduction of cloud computing into the education industry, based on the current education information platform and building a cloud system on it, is a need and a trend of development.

\section{Data Availability}

Data sharing is not applicable to this article as no datasets were generated or analyzed during the current study.

\section{Conflicts of Interest}

The authors declare that they have no conflicts of interest.

\section{Acknowledgments}

This work was supported by the 2020 teaching research project of Wuhan Polytechnic University: A Four-Dimensional Model Construction of Case Base for Translation Courses (Project Number: XZ2020011). Moreover, it was supported by the 2020 Philosophy and Social Science Project of Hubei Province: On the Cultural Identity of Diasporic Translators in the English Translation of Chinese Classics (Project Number: 20D059).

\section{References}

[1] H. Bahri and T. Sepora, "The application of mobile devices in the translation classroom," Advances in Language \& Literary Studies, vol. 7, no. 6, pp. 237-242, 2016. 
[2] W. Kim and G. Byun, "A comparative study of EnglishKorean translations of English major undergraduate and translation major graduate students-focusing on translationeses," The Journal of Mirae English Language and Literature, vol. 22, no. 3, pp. 67-99, 2017.

[3] Y. Yi and T. Angay-Crowder, "Multimodal pedagogies for teacher education in TESOL," TESOL Quarterly, vol. 50, no. 4, pp. 988-998, 2016.

[4] A. F. S. Devaraj, M. Elhoseny, S. Dhanasekaran, E. L. Lydia, and K. Shankar, "Hybridization of firefly and improved multiobjective particle swarm optimization algorithm for energy efficient load balancing in cloud computing environments," Journal of Parallel and Distributed Computing, vol. 142, pp. 36-45, 2020.

[5] N. Suyel and R. Pinki, "PpBAC: popularity based access control model for cloud computing," Journal of Organizational \& End User Computing, vol. 30, no. 4, pp. 14-31, 2018.

[6] N. Oulhen, B. J. Schulz, and T. J. Carrier, "English translation of Heinrich Anton de Bary's 1878 speech, 'Die Erscheinung der Symbiose' ('De la symbiose')," Symbiosis, vol. 69, no. 3, pp. 131-139, 2016.

[7] K. Sunagawa, "Guyton's venous return curf should be taught at medical schools (complete English translation of Japanese version)," The Journal of Physiological Sciences, vol. 67, no. 4, pp. 1-12, 2017.

[8] A. A. Naqvi, M. A. Hassali, A. Jahangir, M. N. Nadir, and B. Kachela, "Translation and validation of the English version of the general medication adherence scale (GMAS) in patients with chronic illnesses," Journal of Drug Assessment, vol. 8, no. 1, pp. 36-42, 2019.

[9] R. Yang, "Internationalization and globalization in higher education," Ryuhei Wakasugi, vol. 30, no. s2-3, pp. 246-258, 2017.

[10] F. Ztemel, "Transmission of cultural specific items in English translation of "dear shameless death" by Latife Tekin," International Journal of Languages Education \& Teaching, vol. 5, no. 1, pp. 302-320, 2017.

[11] D. H. Jarvis, "Digital literacies in education: creative, multimodal and innovative practices," International Review of Education, vol. 62, no. 5, pp. 1-4, 2016

[12] J. A. Watson, "Role of a multimodal educational strategy on health care workers' handwashing," American Journal of Infection Control, vol. 44, no. 4, pp. 400-404, 2016.

[13] S. M. Harman, R. Blankenburg, J. M. Satterfield et al., "Promoting shared decision-making behaviors during inpatient rounds," Academic Medicine, vol. 94, no. 7, pp. 1010-1018, 2019.

[14] A. H. Blitz-Raith, J. Liu, and J. Liu, "Interactivity in educational apps for young children: a multimodal analysis," International Journal of Instruction, vol. 10, no. 4, pp. 237-254, 2017.

[15] R. Jeff, P. Catherine, L. Michelle, and J. Sherbino, "JGMEALiEM hot topics in medical education: analysis of a multimodal online discussion about team-based learning," Journal of Graduate Medical Education, vol. 9, no. 1, pp. 102-108, 2017.

[16] J. Hatley, "Universal values as a barrier to the effectiveness of global citizenship education: a multimodal critical discourse analysis," International Journal of Development Education and Global Learning, vol. 11, no. 1, pp. 87-102, 2019.

[17] A. Rabiolo, I. Zucchiatti, A. Marchese et al., "Multimodal retinal imaging in central serous chorioretinopathy treated with oral eplerenone or photodynamic therapy," Eye, vol. 32, no. 1, pp. 55-66, 2018.
[18] I. Doumanis, D. Economou, G. R. Sim, and S. Porter, "The impact of multimodal collaborative virtual environments on learning: a gamified online debate," Computers \& Education, vol. 130, pp. 121-138, 2019.

[19] C. W. Huang and A. Archer, "Academic literacy' as moving beyond writing: investigating multimodal approaches to academic arguments," London Review of Education, vol. 15, no. 1, pp. 63-72, 2017.

[20] A. M. Wiseman, M. Mäkinen, and R. Kupiainen, "Literacy through photography: multimodal and visual literacy in a third grade classroom," Early Childhood Education Journal, vol. 44, no. 5, pp. 537-544, 2016. 